\title{
Experimental Researches Regarding the Manufacturing of New Thermoplastic Materials Used in Additive Technologies
}

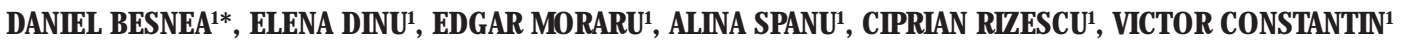 \\ 'Politehnica University of Bucharest, Splaiul Independenei no. 313, 060042 Bucharest, Romania

\begin{abstract}
The article presents the process of manufacturing by adding solid state material (thermoplastic extrusion) in order to achieve new composite deposition materials and to provide new models, raw materials and functional prototypes with superior mechanical features and characteristics. The authors describe the extrusion device as well as the parts manufactured of thermoplastic material.
\end{abstract}

Keywords: additive technologies, material extrusion, composite materials

During the end of the last century, the emergence of new fabrication technology by the adding of material is considered a milestone in research and technological development. These additive manufacturing processes are the effect of extensive researches and scientific development in different domains of application: precision engineering, laser processes, materials science, medicine and many more others. Additive manufacturing systems can generate a special flexibility in application, which is a benefit that is exploited for the manufacturing of various pieces with superior dimensional accuracy used as conceptual exemplaries, functional parts or indirectly used as a prototype for the obtaining of functional components in the production of customized metallic and polymeric pieces $[1,2,12,14]$.

There are several additive manufacturing processes, all with the advantages and disadvantages for the application areas. Existing additive technologies are classified based on various characteristics, like the type of material used, the state of this material and the operation method. It was implemented a set of standards [3] in order to classifies technologies based on adding material to seven major categories: vat photopolymerisation [4] , binder jetting, material jetting, material extrusion [5], powder bed fusion [6], sheet lamination and direct energy deposition.

The fused deposition modeling method applied in this study typically uses two materials: polylactic acid - an ecological thermoplastic material obtained by processing plants such as corn, sugar beet and acrylonitrile butadiene styrene, which is a mechanically superior thermoplastic, used in many industries, being a material especially for engineers $[3,11]$.

\section{Experimental part}

The objectives of the paper are aligned with the global tendency in using additive fabrication systems in the production, development or modernization of products by implementing functional models or prototypes with acceptable accuracy and low cost. Following the challenges presented above, an extrusion system has been designed and manufactured. It allows the use of PLA and $A B S$ based raw materials in combination with some admixtures as a new solution for providing the possibility of obtaining new types of composite materials, which is the basis material the parts with complex geometries and superior features are made of by using additive technologies. The benefits of the technolgy consist by the feasibility of rapid obtaining of working pieces as well as indirect use of the parts manufactured by the FDM process with the new composite material provided in the extrusion device as a master model in order to obtain adaptable working instruments used for the realizing of the objects in the customized production or limited number of parts. Another advantage represents the disposal of waste, so the fused deposition modelling technology is simply to use and and has no restrictions on special equipments or operating circumstances. The major disadvantage is the reduced accuracy $(0.1-0.2 \mathrm{~mm})$ and the low quality of the manufactured surfaces. 13].

A section of the extrusion device is shown in figure $1[7$,

For the actuation of the worm screw, it was used the Baureihe $0277 \mathrm{DC}$ motor with a torque of $5 \mathrm{Nm}$, a nominal voltage of $24 \mathrm{~V}$ provided with a 78/1 transmission reducer. The precise control of the speed of the worm screw and of the temperature in the heating resistors is obtained by means of an Arduino Uno development board. The logical diagram of the stand and the block diagram of the software are represented in figure 2. Figure 3 shows a sequence of the Arduino code used to control the temperature distribution.

The experimental set-up was designed using specialized software (fig.4) and a thermal model was developed in the multiphysical analysis software, showing

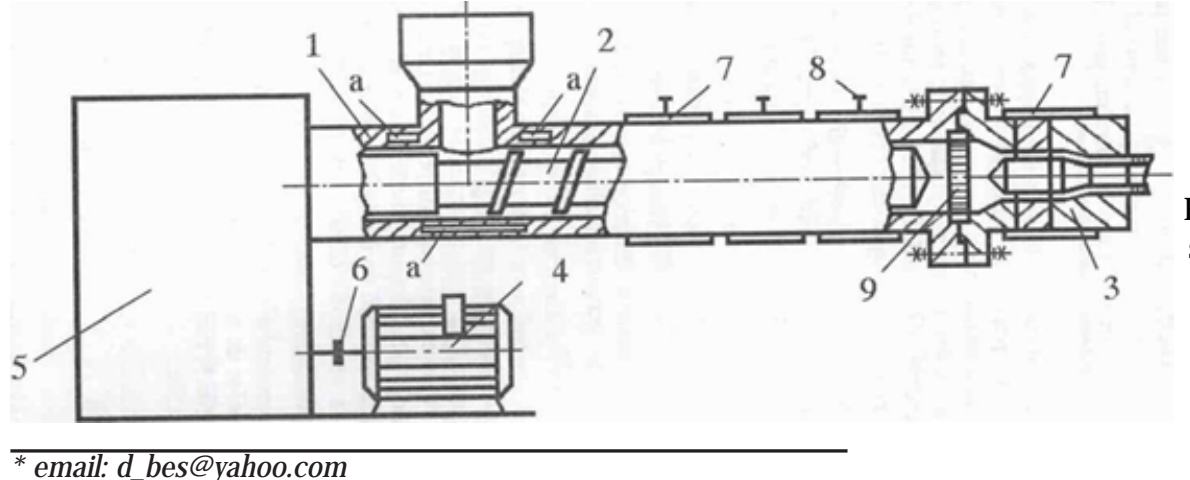

Fig.1 Extrusion device. 1 - Cylinder; 2 - Worm screw; 3 - Extrusion head; 4 - Electric motor; 5 - Reducer; 6 - Coupling; 7 - Electrical resistance; 8 - Thermocouple; 9 - Sieve 


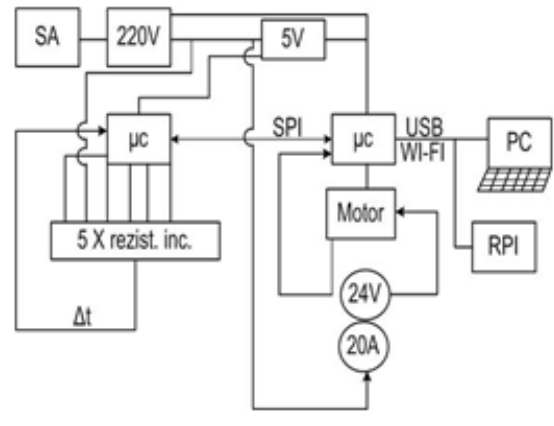

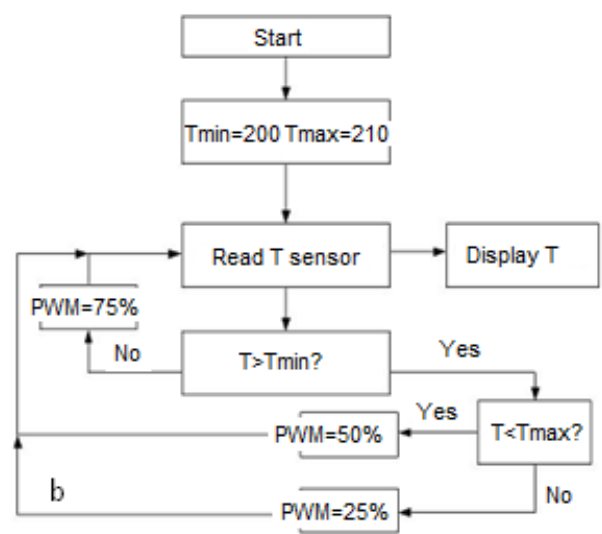

Fig.2. a - The logical scheme of the stand; b - Block scheme of the program
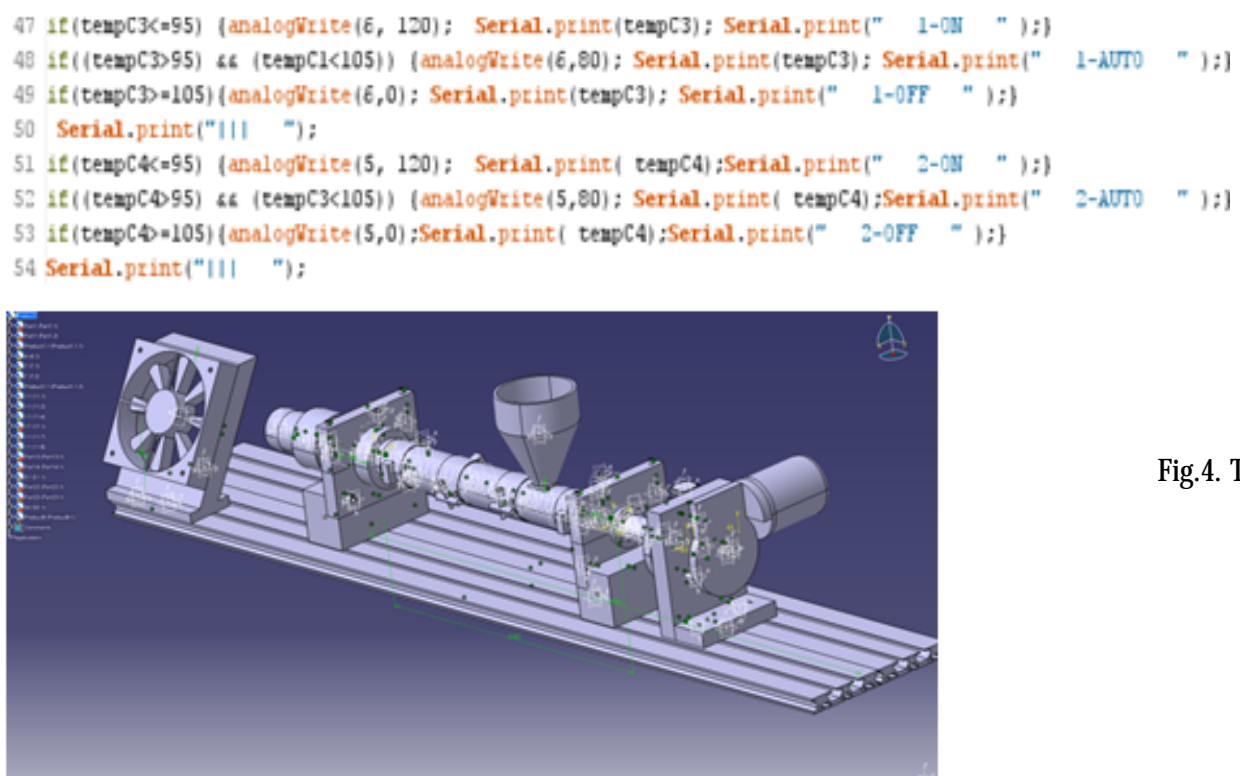

Surface: Temperature $(K)$

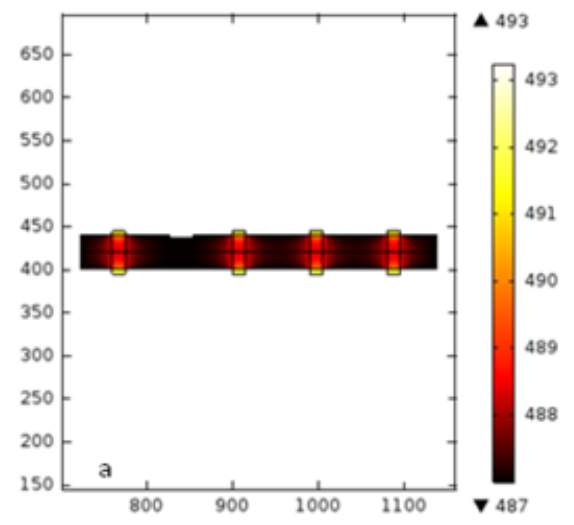

Contour: Temperature $(\infty)$

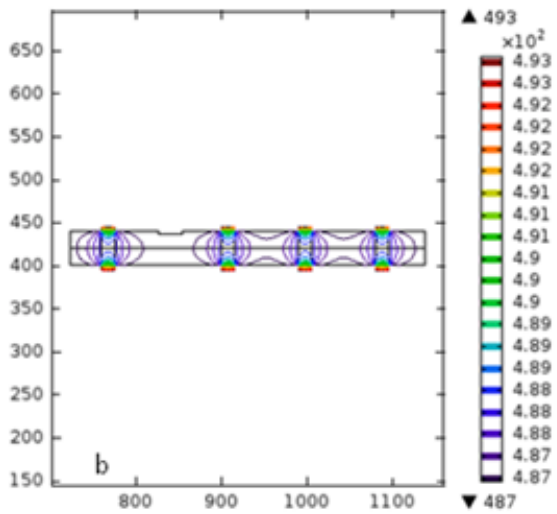

Fig.4. The CAD model of the stand [8]

Fig.5. Thermal model of the electrical resistance -cylinder subassembly. a - Distribution of temperature in the structure; $b$ - Isothermal contours [9]
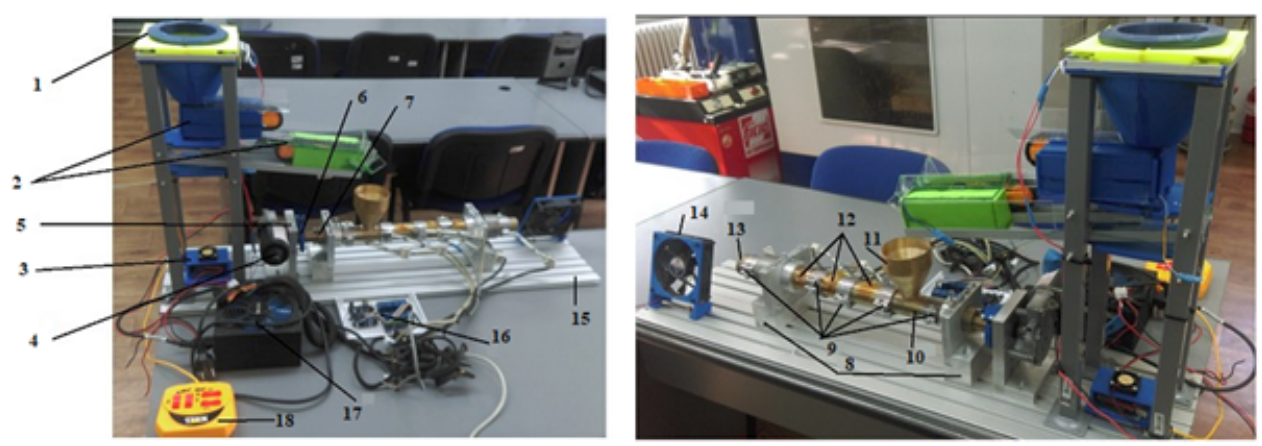

Fig.6. General view of the demosntrative stand in the laboratory. 1 -vat storage of raw material; 2 -raw material transportation system; 3 electronics for motor speed control; 4 -electrical motor; 5 -electrical motor support; -6- rotation transducer; 7 -coupling; 8 -support; 9 -heat resistance; 10 -cylinder; 11 -vat; 12 -sensors for temperature control; 13 -nozzle; 14 -fan; 15 -base plate; 16 - electronic mounting controller with electrical resistance heating relays; 17 -source power supply; 18 -control for transportation system 

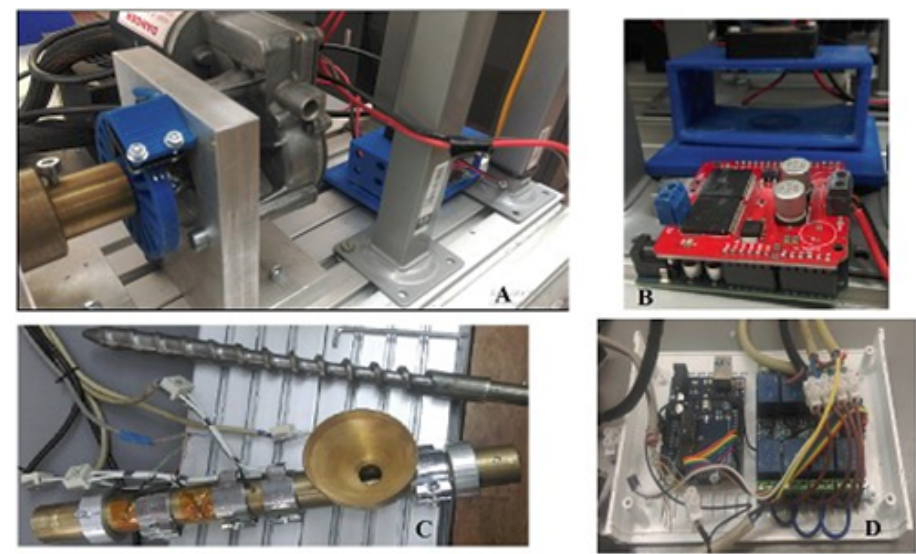

Fig.7. Construction details of the stand:

A - constructive shaft rotation sensor detail;

B - electronics for motor speed control; C - cylinder and worm screw constructive detail; D -controller with electrical heating resistors for heating the polymer material the distribution of the heat flow in the electrical resistance - cylinder subassembly (fig.5). This model is a simplified bidimensional subassembly consisting of a cylinder and four electrical resistances. From the figure 5 it is possible to inferr how the temperature is uniforme distributed from the electrical resistances, where the maximum temperature values (493 K) are reached.

Figure 6 and figure 7 show the general view of the demonstration extrusion set-up and some constructive details, respectively. Following the tests performed at the engine imposed rotational speed of worm screw of 20 RPM and the temperature of electrical resistances of $220^{\circ} \mathrm{C}$, it was observed that the extruded filament is suitable for being used in the next manufacturing step. In this study various thermoplastic and composite materials were used as the raw material for the extrusion of the filament. The best performance was obtained in the case of polylactic acid granules (PLA) (fig. .8).

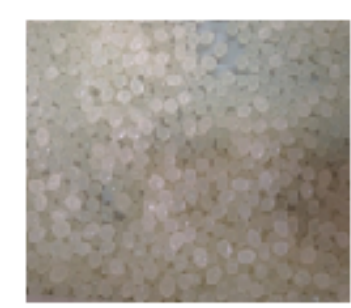

a

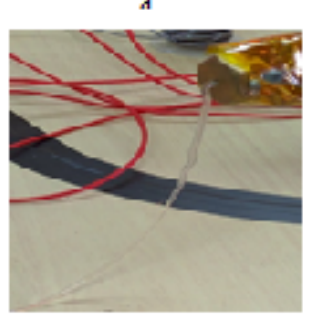

h

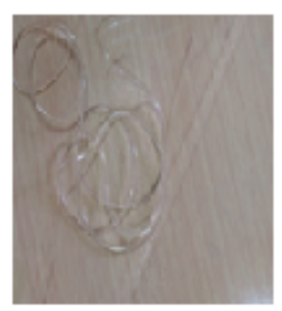

c

Fig.8. PLA thermoplastic material: a - PLA granules; $b$ - extrusion of the filament; c - realized filament

\section{Results and disscusssions}

The thermoplastic extrusion process consists of three principal stages. In the first step the three-dimensional object is designed using specialized software (fig.9) and after that the designed model is loaded into the specialized program Cura (fig.10). This software generates the command code of the FDM equipment. Meantime, the CAD model is positioned in the work area of the machine, so that the manufacturing of the workpiece is optimal in terms of construction time $[1,2]$.

In the stage of piece manufacturing, the model is realized layer by layer and the extrusion head is depositing a thin construction filament $(1.75 \mathrm{~mm})$ along the curves defining the section perimeter. After the obtaining of the perimeters, the thermoplastic material is deposited in the regions corresponding to the entire volumes of the workpiece. If necessary, the sacrificial layers are used, which serve as a support for the workpiece. Finally, it is

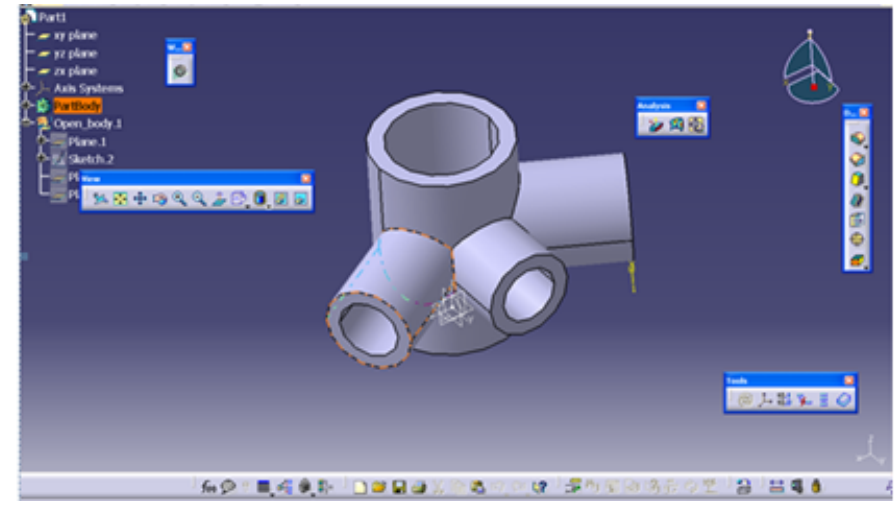

Fig.9. Design of the three - dimensional model [8]

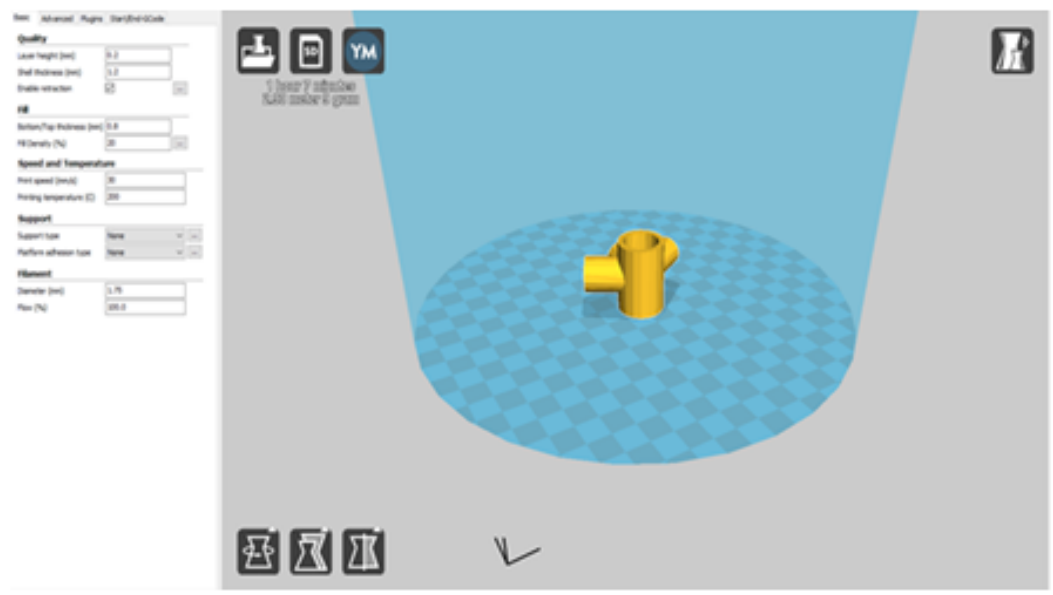

Fig.10 Cura software interface [10] 

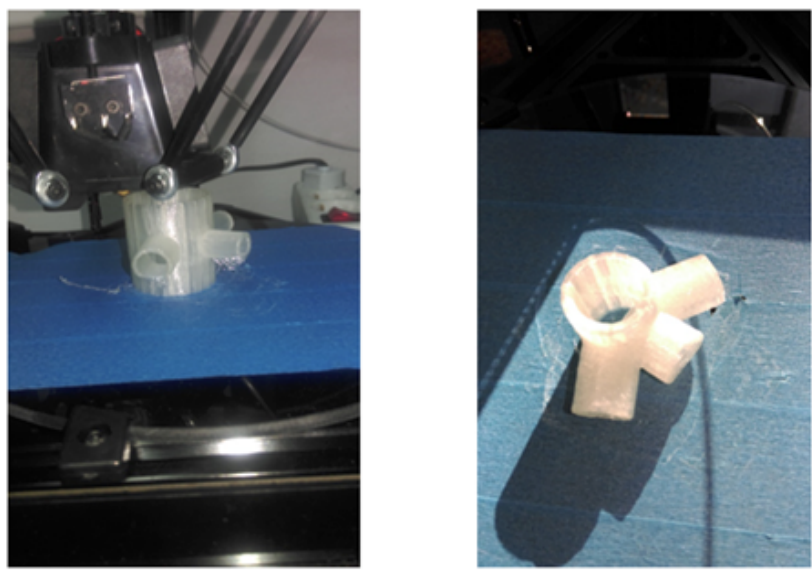

Fig.11. Obained part through FDM (Fused deposition modeling)

eliminated in the last stage - the post-processing stage, which consists of separating the workpiece from the platform and finishing the workpiece if necessary. Figure 11 shows the piece obtained by the FDM technique, which can be used as a model or even as a functional prototype in various applications.

\section{Conclusions}

The authors presented some new advantages of the well-known additive technologies - FDM (Fused Deposition Modeling). Some aspects of the methods of obtaining new thermoplastic and composite materials for the manufacture of parts with superior functional properties are described. A filament extrusion system for FDM technology has been designed and developed. It was also simulated the temperature distribution in the electrical resistances - cylinder subassembly and it has been validated by the experimental tests, obtaining close values of the temperature. In the end, the parts with remarkable mechanical features were obtained from the filament achived with the developed extrusion system. These processes will open new borders for designers and engineers, based on the almost limitless complexity of executable geometries, a new configuration possibilities for making parts that are impossible to manufacture so far in terms of technological possibilities. Thus, Rapid Prototyping proves to be not only a consistent application in product development, but a stand-alone part of manufacturing systems, which will certainly have a hard word in the modern technological world.

\section{References}

1. BERCE P., BALC N., CAIZAR C., PACURAR R., RADU A.S., BRATEAN S., FODOREAN I., Tehnologii de fabricatie prin adaugare de material si aplicatiile lor, Editura ACADEMIEI ROMANE, Bucuresti, 2014.

2. BERCE P., BALC N., ANCAU M., COMSA S., CAIZAR C., CHEZAN H., Fabricarea rapida a prototipurilor, Editura TEHNICA, Bucuresti, 2000. 3. KUMBHAR N.N, MULAY A.V., J. Inst. Eng. India Ser. C, 99, no.4, 2018, pp. 481-487

4. MORARU E., BESNEA D., DONTU O., GHEORGHE G.I., CONSTANTIN V. Applications of Additive Technologies in Realization of Customized Dental Prostheses. In: Gheorghe G. (eds) Proceedings of the International Conference of Mechatronics and Cyber-MixMechatronics - 2018. ICOMECYME 2018. Lecture Notes in Networks and Systems, vol 48. Springer, Cham

5. MORARU E., DONTU O., BESNEA D., CONSTANTIN V., Study and realization of prosthetic dental models by additive technologies, IOP Conf. Series: Materials Science and Engineering 444 (2018).

6. MORARU E., DONTU O., PETRE A., VAIREANU D., CONSTANTINESCU F., BESNEA D., Journal of Optoelectronics and Advanced Materials, 20, no. 3-4, 2018, pp.208-213

7. TEODORESCU N., JUGANARU M.R., Masini si instalatii pentru prelucrarea materialelor polimerice, Editura RENAISSANCE, Bucuresti, 2011.

8. *** CATIA Infrastructure User Guide - CATIA design

9. PRYOR R.W., Multiphysics using Comsol, A first principles approach, by JONES and BARTLETT Publishers, 2011.

10. *** Cura software manual.

11. GABOR, A., HOSSZU, T., ZAHARIA, C., KOZMA, A., COJ OCARIU, A. C., NEGRUTIU, M. L., SZUHANEK, C., SINESCU, C., 3D Printing of a mandibular bone deffect, Mat. Palst., 54, no. 1, 2017, p. 29 - 31.

12. POPESCU, A., ENCIU, G.,DOBRESCU, T., PASCU, N. E., Experimental research using the $3 \mathrm{D}$ printing technology with plastic materials for prehension systems jaws, Mat. Plast., 55, no. 1, 2018, p. 20 - 23.

13. JINESCU, C. V., TEODORESCU, N., Extruder performance based on a correlated extruder head-screw-barrel unit working field, Mat. Plast., 52, no. 1, 2015, p. 1 - 3.

14. DOICIN, C. V., ULMEANU, M. E., NEAGU, C., POPA, L., Designing and prototyping a bespoke spinal implant using additive technologies, Mat. Plast., 53, no. 1, 2016, p. 139 - 143.

Manuscript received: 6.12 .2018 